\title{
SPATIO-TEMPORAL WATER QUALITY MAPPING USING SATELLITE DATA AROUND A MANGROVE PLANTATION IN CAGSAO, CALABANGA, CAMARINES SUR
}

\author{
Khim Cathleen M. Saddi \\ Faculty of Management and Development Studies, University of the Philippines Open University, Los Baños, Laguna, Philippines \\ Department of Civil Engineering, Ateneo de Naga University, Naga City, Philippines - ksaddi@gbox.adnu.edu.ph
}

KEY WORDS: Image Processing, Water Quality Mapping, Mangroves, Spatio-temporal analysis

\begin{abstract}
:
The Cagsao mangrove is a thriving young forest along the San Miguel Bay (SMB), Camarines Sur. To establish the Spatio-temporal Water Quality mapping, data from the Chesapeake Bay, an estuary in the United States of America (USA), was sourced as the train set for this study. Spatio-temporal maps of chlorophyll and dissolved oxygen were generated using Linear Regression (LR) models which were derived from the train set and satellite images of the SMB. GNU (GNU's not UNIX) Octave was used for the image processing, computing, and analysis. There were three phases in the image processing conducted in this study, 1) extraction of image data of the corresponding measure points from the train area, 2) conversion of the satellite study area to a two-color raster image, and 3) generation of the spatio-temporal maps from the analysis. The study found that the SMB is in the range of Mesotrophic to Moderate Eutrophic classification. The decay from two other point sources (Manga River and Libmanan River) was compared to that of Tigman River, an adjacent river to the Cagsao mangrove forest to determine variations and impact of the mangrove forest in the water quality of the SMB. The presence of Cagsao mangrove forest was found to affect the gap of increasing chlorophyll levels from shore toward the bay center in the adjacent Tigman River unlike Manga River and Libmanan River, which have both no adjacent mangrove forest in the river mouth area. The corresponding satellite images for the dataset taken during and near the date of the train area measurements were also extracted.
\end{abstract}

\section{INTRODUCTION}

\subsection{Coastal Waters and the Mangroves}

The annual impact of economic and social activities in Coastal Regions amounting to billions of dollars in the global scene (Costanza, et al., 1997; Martinez, et al., 2007) shows the importance and need for sustainable coastal water management. It was estimated that several kilometers per year of aquaculture areas can erode posing danger to coastal communities (van Wesenbeeck, et al., 2015).

Apart from potential benefits to ecotourism, these ecosystems also provide researchers with various habitats for the conduct of extensive coastal research (Mallin \& McIver, 2012).

One of the natural defenses available to ocean degradation is the presence of mangrove forests. A mangrove forest commonly serves as a habitat for juvenile aquatic animals and other marine animals which seek refugee during periodic seasons or typhoons. The most recognized ecosystem services of mangrove forests include serving as a carbon sink and as ocean greenbelts protecting coastlines from from tsunamis and storm surges (Alongi, 2008; Barbier, S. D. Hacker, Koch, \& Stier, 2011). These forests are critical agents for coastal area protection (Veettil \& Quan, 2019) and curb climate change effects. However, over $35 \%$ of the total mangrove cover worldwide, has disappeared due to clearcutting and aquaculture ponds conversion since the 1980s (Richards \& Friess, 2016).

\subsection{Physio-Chemical Parameters}

Several studies have been published about the association of physio-chemical and microbiological pollutants' monitoring, evaluation, distribution, and transformation to water quality and sediments in coastal estuaries (Gao, Falconer, \& Lin, 2013; Camilion, Manassero, Hurtado, \& Ronco, 2003; Amsler \&
Drago, 2009; Manbohi \& Gholamipour, 2020). High concentrations of nutrients and hydro-chemical substances including silicate, nitrate, and phosphate later results in the eutrophication of marine waters (Marengo, Gennaro, Giacosa, Saini, \& Avignone, 1995). Parameters common in several studies include $\mathrm{NO} 3, \mathrm{NO} 2, \mathrm{NH} 4, \mathrm{PO} 4, \mathrm{SiO} 3, \mathrm{pH}$, water temperature, salinity, dissolved oxygen (DO) concentration, electrical conductivity (EC), turbidity, suspended solids and fecal coliforms (Norat-Ramírez, P.Méndez-Lázaro, E.A.Hernández-Delgado, H.Mattei-Torres, \& L.Cordero-Rivera, 2019; Manbohi \& Gholamipour, 2020). It is important to establish the characteristics based on these parameters to have a better understanding of a marine environment (Wu, Wang, Wang, Dong, \& Han, 2009). It was found that nutrient concentration is significantly higher in the wet season and decreases with offshore waters (Manbohi \& Gholamipour, 2020).

One of the important indicators of a thriving marine life is the level of plant-producing organisms and dissolved oxygen present, as a source of food and oxygen, respectively. Phytoplankton are microscopic marine algae which hold the base of several aquatic food webs. Also called microalgae, they contain chlorophyll and need sunlight, hence they live in the surface waters (NOAA, 2019). Marine productivity and capture of greenhouse gases (GHGs) are closed-related to the function and structure of planktonic communities (Karl, Bidigare, \& Letelier, 2001).

The regulation and variability of the concentration of dissolved oxygen are primary to the function of the marine ecosystem since it supports marine life. It was found in the correlation maps of the Mediterranean Sea that the DO in the surface waters were dependent on solubility with some temperature factor in contrast to the deep waters where DO was primarily influenced by dynamical processes like density, circulation, or transients (Mavropoulou, Vervatis, \& Sofianos, 2020). 


\subsection{Water Quality Monitoring}

Biomonitoring is essential in cases of water pollution accidents (Schalie, Shedd, \& Widder, 2001). Principal component analysis is generally used to interpret the characteristics of water. It works by separating data points into clusters while establishing relationships among the different variables (Qu \& Kelderman, 2001). Several water quality studies focus on temporal analysis (Astel, Mazerski, Polkowska, \& Namieśnik, 2004) and spatial variation mapping (Astel \& Simeonov, 2011). The use of septic weight index was proved as an accurate predictor in near shore water quality as well (Norat-Ramírez, P.Méndez-Lázaro, E.A. Hernández-Delgado, H.Mattei-Torres, \& L.Cordero-Rivera, 2019). Numerical modeling was found to be an important tool in the planning, management, and decision-making to reduce wastewater discharge (Doan, Nguyen, Quach, Tran, \& C.D.Nguyen, 2019). In data-driven modeling, the most pressing issue is the creation of a probabilistic model with logical arguments and its accuracy to represent a phenomenon (Kim \& Park, 2017).

Along the coastlines of Asian countries, mangrove forests have consistently declined and are under serious threat primarily due to unsustainable practices such as aquaculture (Ward, Friess, Day, \& Mackenzie, 2016). With satellite images, changes in mangrove forests over the decades can be analyzed (Veettil \& Quan, 2019), quantify and forecast. Mangroves attenuate both waves (Winterwerp, Erftemeijer, Suryadiputra, Eijk, \& Zhang, 2013) and tidal currents (Mazda, et al., 1997). These natural warriors also help prevent erosion and enhance sediment accretion (Chen, et al., 2018). In Senegal, despite community interaction, mangrove forests exhibited significant gains (Andrieu, et al., 2020).

Spatio-temporal mapping is the key to understanding the variations in water quality parameters and maintaining the health and safety of both the water and aquatic ecosystems (Chu, Kong, \& Chang, 2018).

However, in-situ monitoring is labor-intensive and is not viable in some areas, especially during spawning months. The combination of using Remotely Sensed (RS) data with in-situ water quality measurements has provided both a significant and cost-effective evaluation of water quality variations (Devlin, et al., 2015) and monitoring.

\subsection{The Mangrove Plantation in Cagsao}

With approximately over 6 hectares of mangrove cover, the study area is a once deserted shore part of San Miguel Bay fronting the Pacific ocean, in the province of Camarines Sur (Faustino, Madela, Castor, Muroda, \& Chavez, 2020). Specifically, the mangrove forest is in Barangay Cagsao, Calabanga, a coastal village where several houses were lost during a storm surge back in 1998 (Soltes \& Rodriguez, 2010). It was the year 2009 when volunteers started coming to plant mangroves in the area including students, teachers, health professionals, and even foreigners. Various groups found interest in the rehabilitation of the mangrove and in cooperation with the LGU of Calabanga and DENR, Smart Communications spearheaded the rehabilitation. It was as early as 2010 that increases in stocks of crablets were reported, then a ban on the gathering of stocks inside the plantation was banned (Escandor, 2012). The village fishermen are convinced that the mangrove forest provides for the community, it allowed them to catch more fish (Soltes \& Rodriguez, 2010).

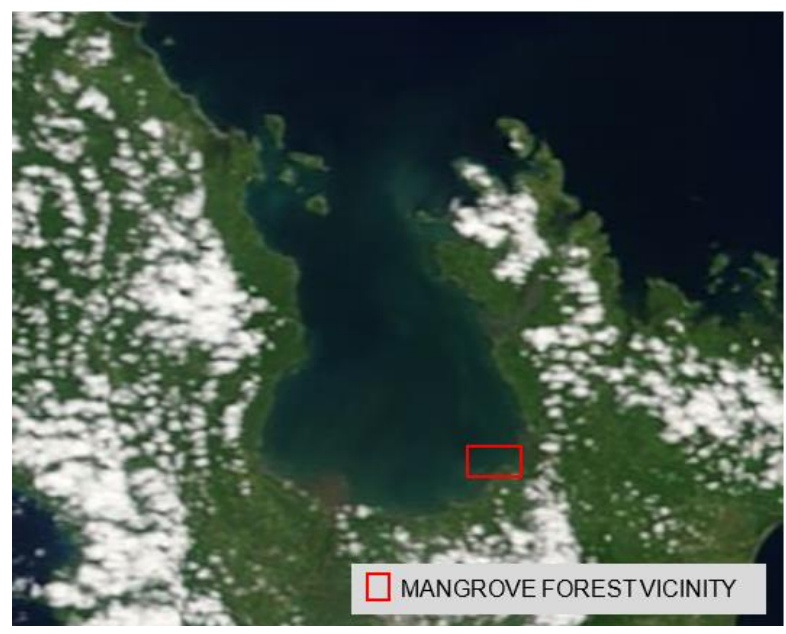

Figure 1. San Miguel Bay (Nasa, 2020)

Local institutions like the Central Bicol State of Agriculture (CBSUA) and Ateneo de Naga University (ADNU) are regularly conducting mangrove planting activities in the area and other mangrove sites in Calabanga to date (Faustino, Madela, Castor, Muroda, \& Chavez, 2020). Shown in Figure 1 the Satellite image of SMB.

\subsection{Train Area}

Home to approximately 3600 species of plants and animals, Chesapeake Bay is the largest estuary in the United States. This bay stretches across six states and is being regularly monitored due to its economic and biodiversity importance (Chesapeake Bay Foundation, 2021).

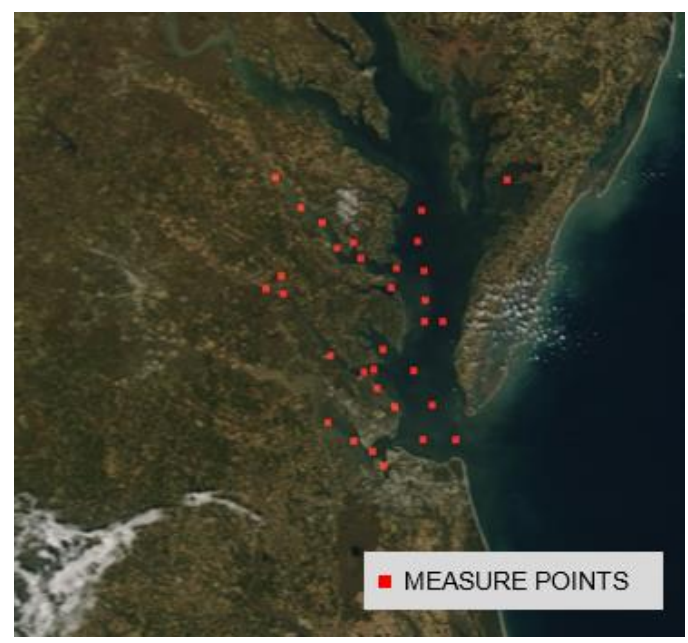

Figure 2. Chesapeake Bay (Nasa, 2020)

The main goal of the study is to use satellite data for a Spatiotemporal water quality mapping around the Mangrove Plantation in Cagsao, Calabanga, Camarines Sur to determine the variations in the water quality surrounding a mangrove forest using Train data from the Chesapeake Bay. As shown in Figure 2, the Satellite image of the Chesapeake Bay with the plotted measure points. 


\section{METHODOLOGY}

\subsection{Image Processing}

To maximize the temporal property of the satellite images, cloud-free images with acquisition dates that are close to the sampling dates of the train area water quality (TAWQ) data were preferred. Masks were made to separate water from land or clouds. Focal mean filtering was also used to enhance spatial patterns and generate a noise reduction. Grey-scale images of all bands were examined first visually to provide an added layer of quality control. It was found that visible bands contain the most information about the spatial distribution of surface waters as reflected in the satellite imagery. Principal component analyses (PCA) were performed to concentrate the important characteristics into one layer and facilitate better recognition of spatial patterns. (Erkkila \& Kalliola, 2004).

GNU Octave was used in the image processing for the study. It is an open-source alternative to Matlab. Image and IO packages were incorporated to perform image processing and extraction of data from MS Excel. Satellite images from NASA with Terra, MODIS, True Color, Corrected Reflectance base layer were used. Cloud-free images were preferred to avoid further image manipulation. Images with excessive cloud cover were replaced with cloud-minimum images taken nearest to the measure dates. There are two sets of satellite images used, the train area (Chesapeake Bay) and the study area (San Miguel Bay).
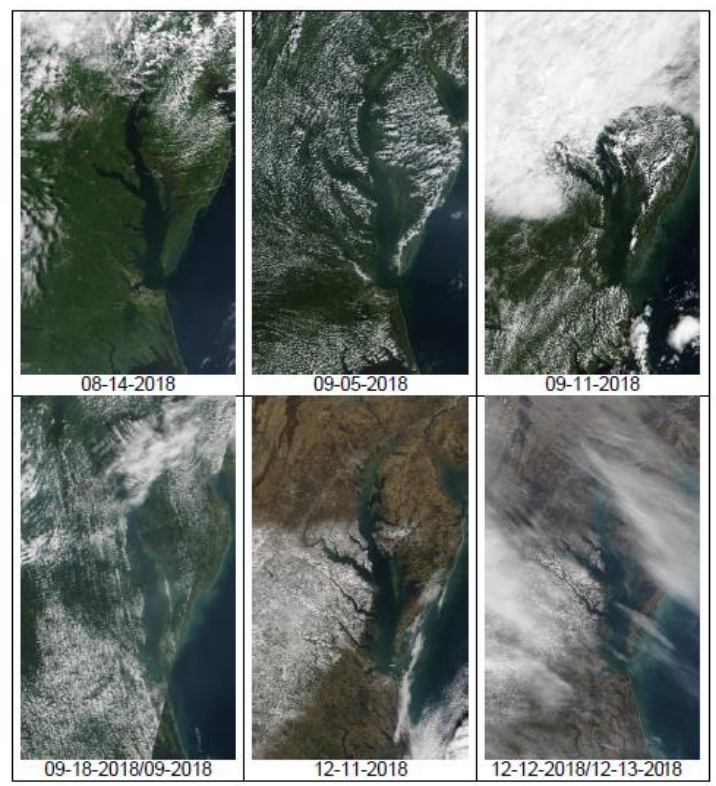

Figure 3. Chesapeake Bay Train Images

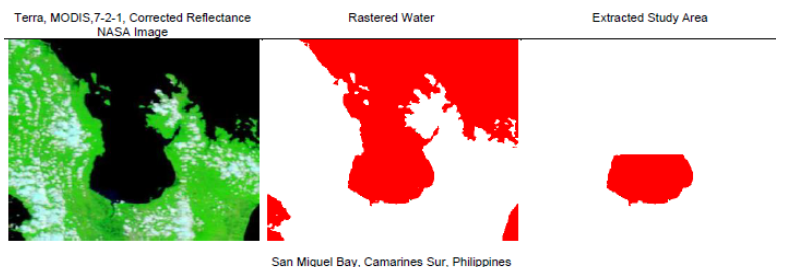

Figure 4. Image Processing Phase 2

The first phase of image processing was the extraction of image data of corresponding measure points from the train area $\mathrm{CB}$ as shown in Figure 3. These data were needed as inputs in the Linear Regression (LR) Model. All three reflectance, Red, Blue, and Green channels, using 8bits each with values 0 to 255 was extracted. There are a total of 6 satellite images (approximately $70 \%$ of the train images) used in this phase.

The second phase of image processing was the conversion of the study area SMB (Terra, MODIS,7-2-1, Corrected Reflectance) satellite imagery to a two-color raster image separating the water (R-255, G-0, B-0) from land (R-255, B-255, G-255). By separating land from water, the coordinates of the study area needed for mapping were extracted. Phase 2 is illustrated in Figure 4.
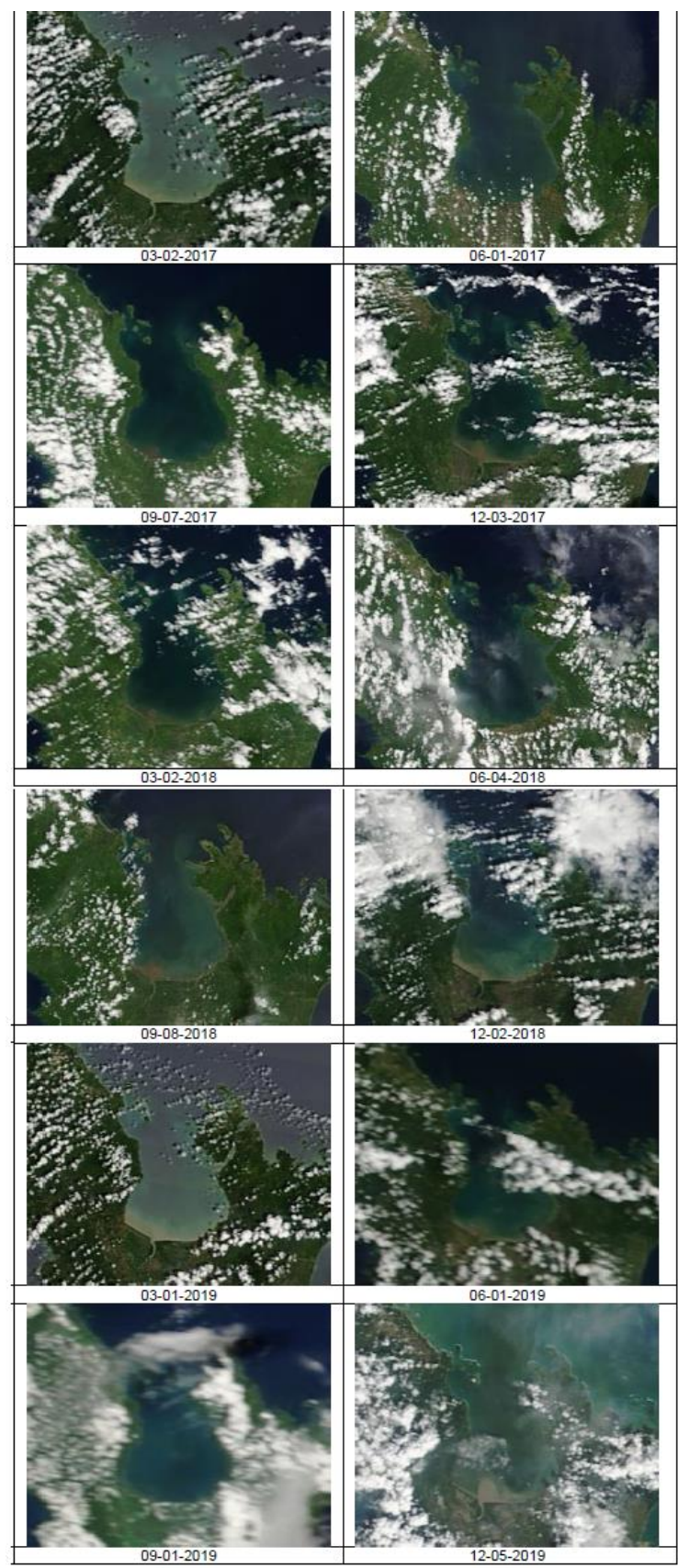

Figure 5. San Miguel Bay Study Images

The third phase uses 12 satellite images of the study area spanning for 3 years, 2017-2019, taken quarterly as shown in Figure 5. From the coordinates generated in the second phase, the image data of the bay for all 12 images was extracted. Only the water data was extracted and cleaned for the next phase. 
The last phase of image processing was the generation of the map reflecting the Spatio-temporal WQ model for chlorophyll and DO for all 12 images. The model-derived values of Chlorophyll and DO were mapped following a color gradient intensity from blue to red.

\section{$2.2 \quad$ LR Model}

Usage of the red, green, and blue reflectance as inputs yields better model results (Chu, Kong, \& Chang, 2018). Linear regression was employed to determine the pattern of water quality around the perimeter of the mangrove reserve. Data extracted from image processing phase 1 were used as variables $\mathrm{R}, \mathrm{G}$, and $\mathrm{B}$ respectively.

$$
Y=\beta o+\beta 1 x 1+\cdots+\beta n x n
$$

$\mathrm{Y}$ value from general equation 1 is the Chlorophyll and DO values, respectively. There are two models generated, the $\mathrm{CH}$ and DO models. Though other studies found that the Geographically Weighted Regression (GWR) models yield better results than LR (Chu, Kong, \& Chang, 2018), establishing the LR models is equally important, since this practice is common (Hellweger, P. Schlosser, \& Weissel, 2004), specifically for lakes and reservoirs (Kloiber, Brezonik, \& Bauer, 2010).

\section{LR Model Coefficients}

\begin{tabular}{ccc}
\hline & $\begin{array}{c}\text { Coefficients, } \\
\text { Chlorophyll }\end{array}$ & $\begin{array}{c}\text { Coefficients, } \\
\text { Dissolved Oxygen }\end{array}$ \\
\hline Intercept & 36.36317148 & 3.038763862 \\
R & 0.881006201 & -0.400514632 \\
G & -1.174955019 & 0.186266802 \\
B & 0.177340985 & 0.232943959 \\
\hline Error & 8.845614373 & 1.633666764
\end{tabular}

Table 1. LR Model Coefficients

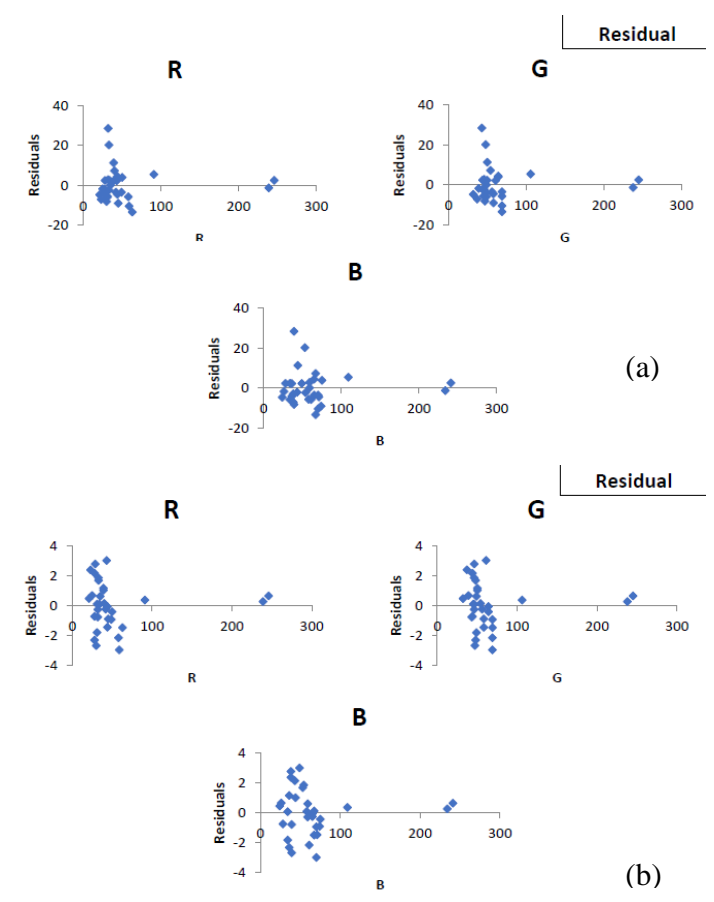

(b)
Shown in Table 1, the LR Model coefficients from the Linear Regression analysis, with 32 observations or data points, from the train set CB. Errors were not incorporated in the LR model. It can be noted that though the B band appears to be statistically insignificant due to its p-value, it was still included in the model due to the uncertainty of the dataset variation should an in-situ measurement for the study area be available. Shown in Figure 67, the residuals and fit plots for Chlorophyll and Dissolved oxygen, respectively.

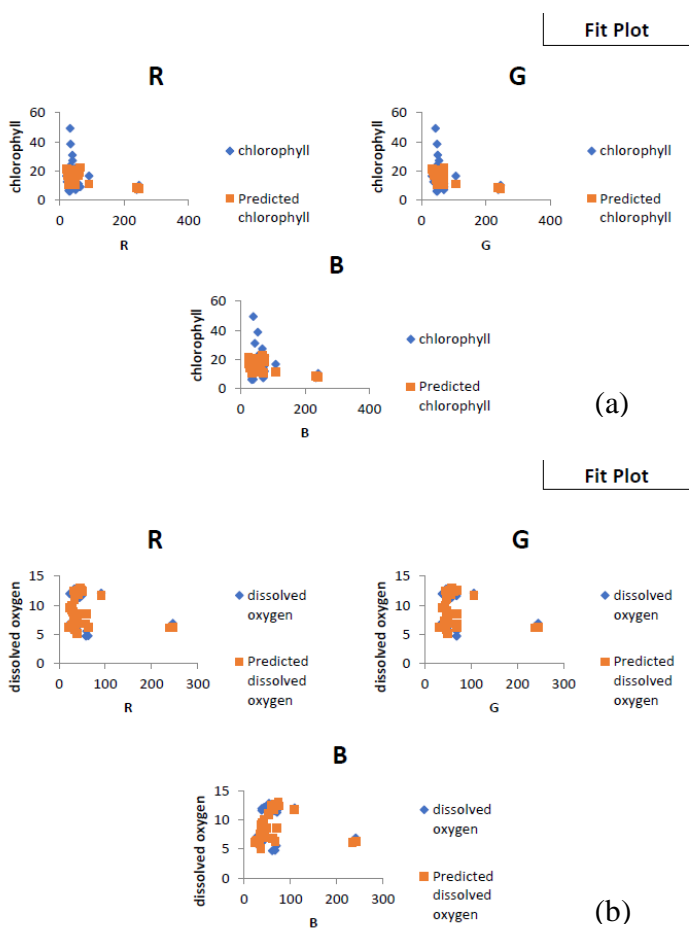

Figure 7. Fit Plot (a) Chlorophyll and (b) Dissolved Oxygen

Both residual plots of chlorophyll and dissolved oxygen in Figure 6, the random dispersal is present only in the range of 0 to 100 for R, G, and B bands. Normally, when randomness in the dispersal is not observed, a non-linear regression is appropriate. However, this may not be the case for this data since there is a limitation in the trains set data used. As shown in Figure 7, the fit plot of dissolved oxygen is better predicted than the chlorophyll. This gap can be accounted by the uncertainties on other factors affecting phytoplankton migration like illumination (Gerbersdorf \& Schubert, 2011).

\subsection{Shore Decay Points}

From Table 1, the LR models were represented by Equations 2 and 3. Both equations were plugged into GNU Octave where computing and image processing and maps were generated.

$$
\begin{aligned}
& C H=36.363171+0.881006 R-1.174955 G+0.163481 B \\
& D O=3.038764-0.400515 R+0.186267 G+0.232944 B
\end{aligned}
$$

Figure 6. Residuals (a) Chlorophyll and (b) Dissolved Oxygen 


\begin{tabular}{cccc}
\hline Point Source & $\begin{array}{c}\text { Decay Point } \\
\text { Code }\end{array}$ & Latitude & Longtitude \\
\hline Manga River & MR1 & 13.7768 & 123.046 \\
& MR2 & 13.7911 & 123.088 \\
& MR3 & 13.8054 & 123.131 \\
\hline Libmanan River & LR1 & 13.7312 & 123.121 \\
& LR2 & 13.7684 & 123.147 \\
& LR3 & 13.8057 & 123.172 \\
\hline Tigman River & TR1 & 13.7756 & 123.299 \\
& TR2 & 13.7928 & 123.257 \\
& TR3 & 13.8099 & 123.216 \\
\hline Note: Decay points start from river mouth toward SMB center with 5 km interval.
\end{tabular}

Table 2. Decay Point Source and Code details

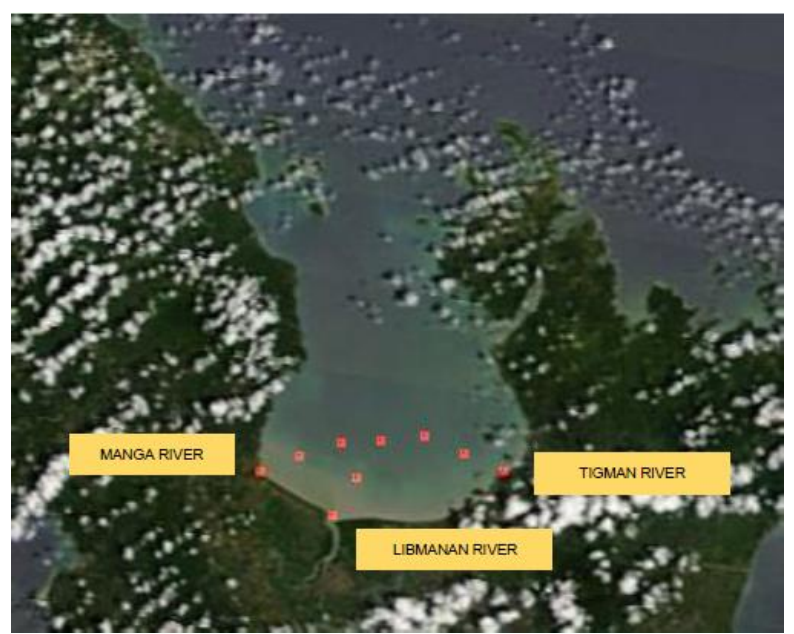

Figure 8. River Mouth and decay points of the three rivers in San Miguel Bay (Nasa, 2020)

The decay shore decay points as illustrated in Figure 8 start with the three (3) rivers, Manga, Libmanan, and Tigman. The MR1, LR1, and TR1 are points at the river mouth while MR3, LR3, and TR3 are points near the bay center.

A three-year data was generated from the quarterly extracted satellite imagery, as processed, as reflected in Table 3-4.

\begin{tabular}{lcccccccccccc}
\hline & \multicolumn{1}{c}{2017} & \multicolumn{1}{c}{2018} \\
& $Q_{1}$ & $Q_{2}$ & $Q_{3}$ & $Q_{4}$ & $Q_{1}$ & $Q_{2}$ & $Q_{3}$ & Q4 & Q1 & $Q_{2}$ & Q3 & Q4 \\
\hline MR1 & 21.62 & 26.58 & 27.49 & 26.84 & 26.58 & 19.40 & 6.23 & 23.58 & 21.23 & 28.40 & 28.93 & 25.01 \\
MR2 & 27.10 & 32.19 & 33.36 & 32.58 & 33.88 & 26.19 & 31.01 & 30.36 & 24.36 & 33.88 & 32.58 & 27.49 \\
MR3 & 27.88 & 31.80 & 33.75 & 34.28 & 34.67 & 32.71 & 31.41 & 32.06 & 26.45 & 33.75 & 32.84 & 26.58 \\
LR1 & 22.53 & 29.58 & 27.49 & 25.53 & 26.19 & 28.54 & 25.27 & 24.62 & 21.49 & 28.14 & 27.49 & 21.36 \\
LR2 & 26.32 & 30.23 & 33.10 & 32.06 & 33.36 & 32.71 & 28.93 & 30.10 & 24.10 & 31.80 & 32.58 & 20.71 \\
LR3 & 26.32 & 32.19 & 33.88 & 32.58 & 34.67 & 31.01 & 31.54 & 32.45 & 26.58 & 31.93 & 33.10 & 28.80 \\
TR1 & 24.75 & 28.40 & 29.06 & 23.58 & 28.27 & 26.71 & 26.84 & 25.40 & 20.45 & 29.84 & 20.84 & 28.67 \\
TR2 & 27.23 & 32.84 & 34.28 & 34.67 & 34.15 & 32.58 & 30.75 & 31.01 & 26.19 & 32.71 & 33.10 & 29.19 \\
TR3 & 27.23 & 32.71 & 34.41 & 32.71 & 34.54 & 33.49 & 30.88 & 31.41 & 26.58 & 33.75 & 33.23 & 28.67
\end{tabular}

Table 3. Model derived Chlorophyll

\begin{tabular}{|c|c|c|c|c|c|c|c|c|c|c|c|c|}
\hline & \multicolumn{4}{|c|}{2017} & \multicolumn{4}{|c|}{2018} & \multicolumn{4}{|c|}{2019} \\
\hline & $Q_{1}$ & $\mathrm{Q}_{2}$ & Q.3 & $Q_{4}$ & $\mathrm{Q} 1$ & Q.2 & Q3 & $Q_{4}$ & $Q_{1}$ & $Q_{2}$ & Q3 & $Q_{4}$ \\
\hline MR1 & 5.15 & 4.44 & 4.31 & 4.40 & 4.44 & 5.47 & 7.36 & 4.87 & 5.21 & 4.18 & 4.10 & 5.15 \\
\hline MR2 & 4.37 & 3.64 & 3.47 & 3.58 & 3.39 & 4.50 & 3.81 & 3.90 & 4.76 & 3.39 & 3.58 & 4.37 \\
\hline MR3 & 4.25 & 3.69 & 3.41 & 3.34 & 3.28 & 3.56 & 3.75 & 3.66 & 4.46 & 3.41 & 3.54 & 4.25 \\
\hline LR1 & 5.02 & 4.01 & 4.31 & 4.59 & 4.50 & 4.16 & 4.63 & 4.72 & 5.17 & 4.22 & 4.31 & 5.02 \\
\hline LR2 & 4.48 & 3.92 & 3.51 & 3.66 & 3.47 & 3.56 & 4.10 & 3.94 & 4.80 & 3.69 & 3.58 & 4.48 \\
\hline LR3 & 4.48 & 3.64 & 3.39 & 3.58 & 3.28 & 3.81 & 3.73 & 3.60 & 4.44 & 3.67 & 3.51 & 4.48 \\
\hline TR1 & 4.70 & 4.18 & 4.09 & 4.87 & 4.20 & 4.42 & 4.40 & 4.61 & 5.32 & 3.97 & 5.26 & 4.70 \\
\hline TR2 & 4.35 & 3.54 & 3.34 & 3.28 & 3.36 & 3.58 & 3.84 & 3.81 & 4.50 & 3.56 & 3.51 & 4.35 \\
\hline TR3 & 4.35 & 3.56 & 3.32 & 3.56 & 3.30 & 3.45 & 3.82 & 3.75 & 4.44 & 3.41 & 3.49 & 4.35 \\
\hline
\end{tabular}

Table 4. Model derived Dissolved Oxygen

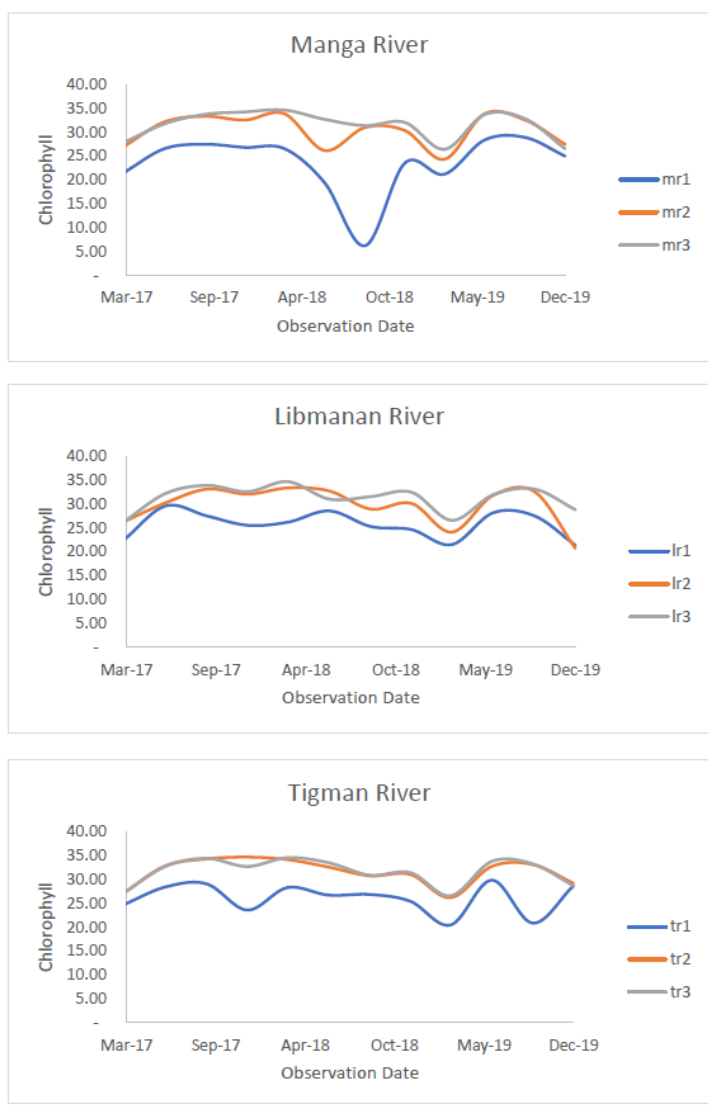

Figure 9. Chlorophyll Shore Decay
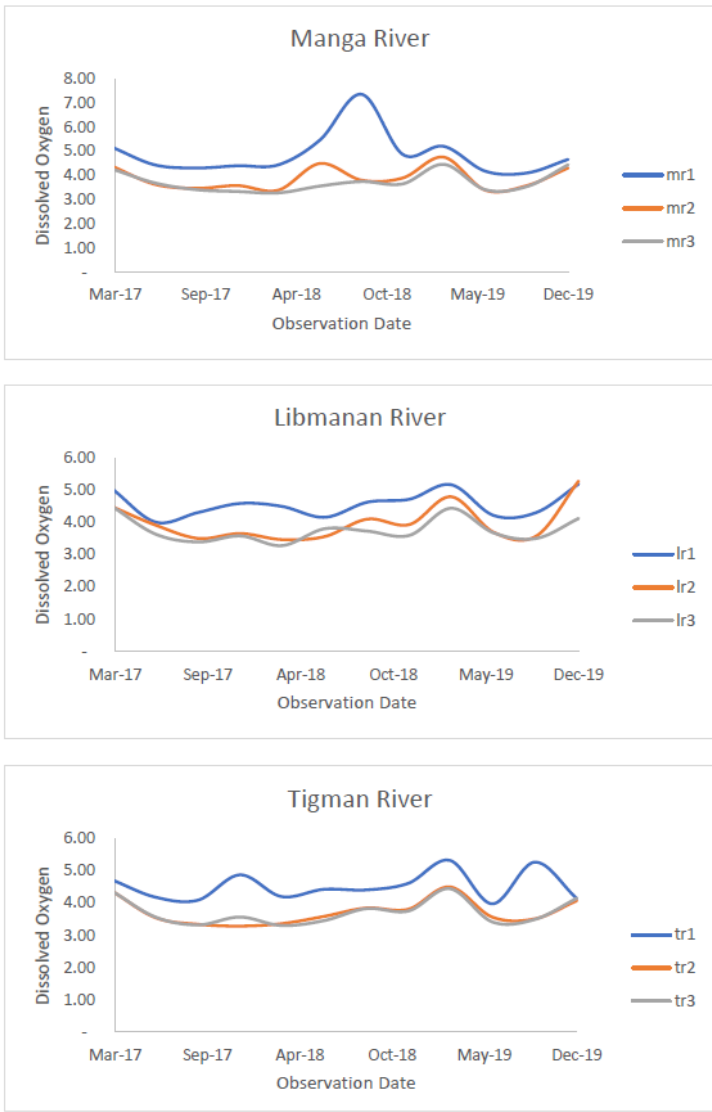

Figure 10. Dissolved Oxygen Shore Decay 
Shown in Figure 9-10 the illustration derived from LR models of Chlorophyll and Dissolved Oxygen for the decay points illustrated in Figure 8. It can be noted that the Chlorophyll shore decay for Tigman River presented a larger gap between TR1 (river mouth) and TR2 while substantially the same levels in TR2 and TR3. A different observation was present to Manga and Libmanan River which have no adjacent mangrove and have a mangrove forest along banks, respectively.

\subsection{Spatio-Temporal Maps}

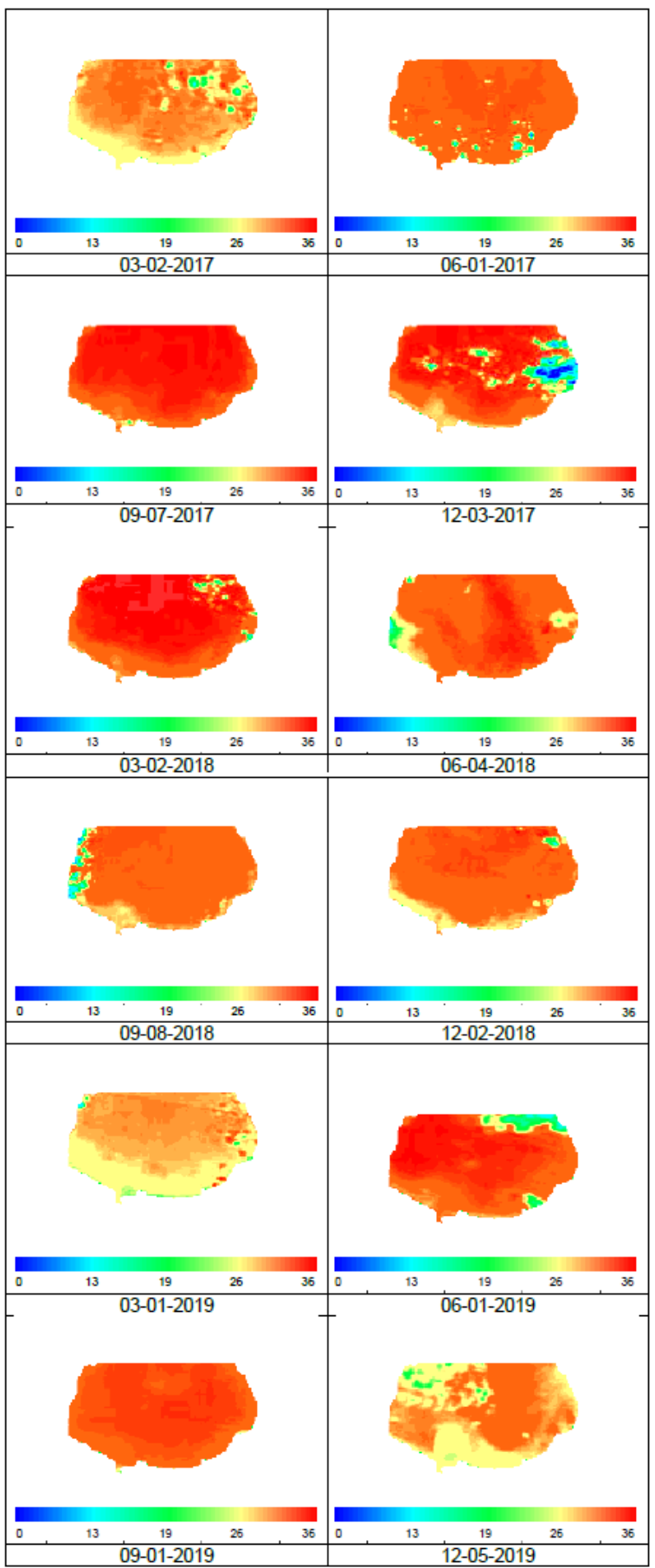

Figure 11. Quarterly Spatio-temporal Map of SMB Chlorophyll (2017-2019)
Illustrated in Figure 11 the Spatio-temporal maps of a portion of SMB subjected to model-derived chlorophyll and dissolved oxygen data. It can be observed that the streamflow of Libmanan River highly affects the level of Chlorophyll present in the waters surrounding its mouth.

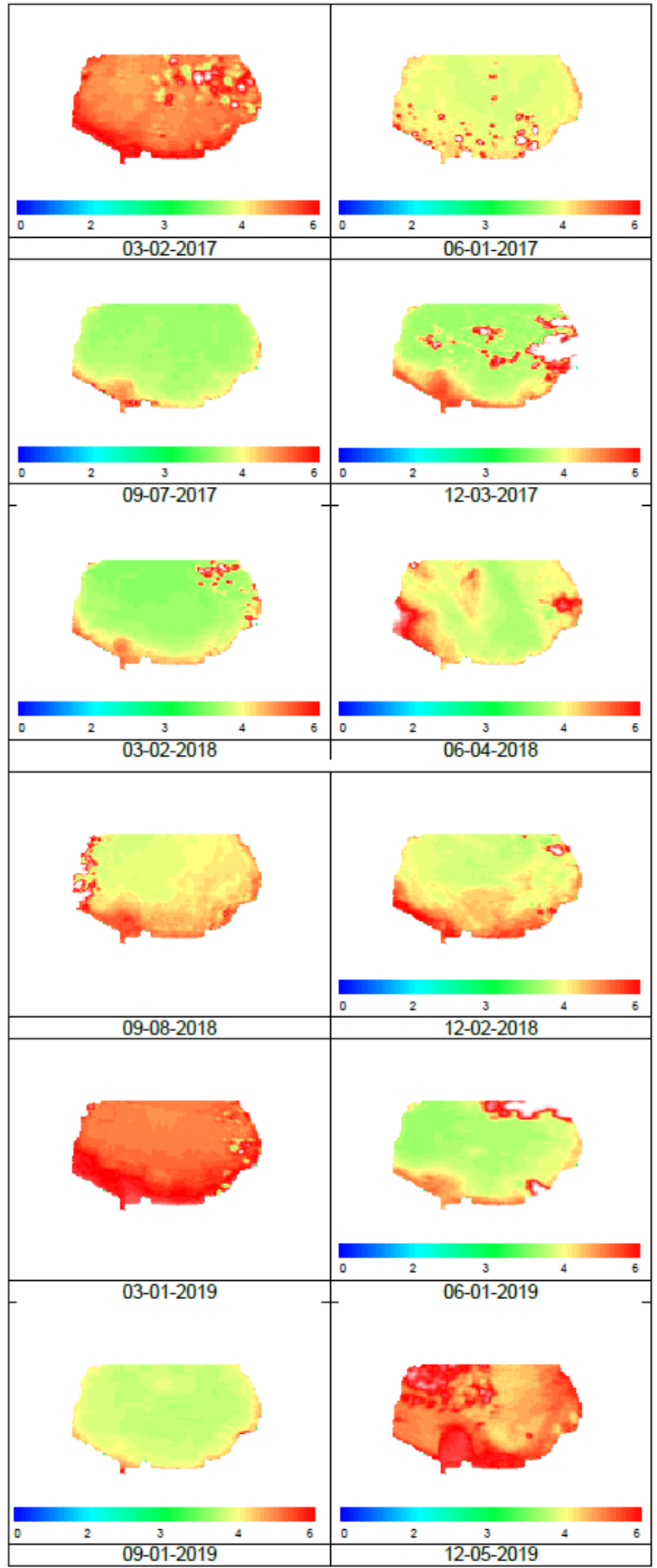

Figure 12. Quarterly Spatio-temporal Map of SMB DO (2017-2019)

While the Tigman River, which is smaller in size, appears to have a smaller range of influence on the chlorophyll levels of the surrounding waters. This can be attributed to the presence of the Mangrove Forest acting as a natural wastewater treatment relative to the adjacent Tigman River. The Manga River, however, does not show a significant effect on the chlorophyll levels of the surrounding water which can be attributed to the 
wind direction during this time of the year (MeteologixPH, 2020). In Figure 12, the Spatio-temporal DO map shows an inverse of the Chlorophyll map.

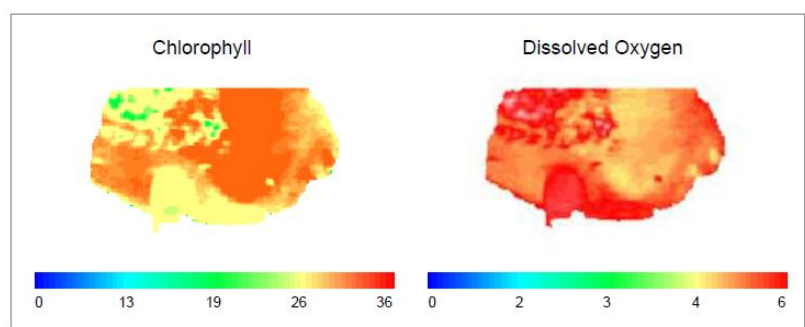

Figure 13. Spatio-temporal Map of SMB (December 2019)

As shown in Figure 13, the side-by-side Chlorophyll and DO Spatio-temporal Map of SMB shows their inverse relationship.

\section{CONCLUSION}

Though LR models were only employed, the generated Spatiotemporal map showed a better illustration of the variations of water quality in San Miguel Bay both for chlorophyll and dissolved oxygen than a one-point comparison. It was clearly presented that the dissolved oxygen is inversely proportional to the chlorophyll present in the surface waters, yet both are important factors in the productivity of aquatic ecosystems such as in San Miguel Bay.

Analysis of shore decay has presented an overview of how DO disperses from the river mouths toward the bay center. This map can also indicate activities that happen in the bay and reflect phenomena and seasonal variations that may affect spawning and fish catch.

Further, the chlorophyll levels in Figure 12 indicate a Mesotrophic to Moderately Eutrophic lake classification. But it is apparent that the Cagsao Mangrove forest played a part in increasing the gap of chlorophyll level variations in Tigman river mouth toward the bay center, unlike Manga and Libmanan river which have no adjacent mangrove and have a mangrove forest along banks, respectively. The levels of dissolved oxygen on the other hand are acceptable with DENR standards for class AA, highest usage classification (DENR, 2016).

To improve the study, the use of more observations and conduct of in-situ water quality monitoring is highly recommended. Measurement of other water quality parameters is also encouraged to be able to deepen the understanding of the variations and patterns of decay in an aquatic ecosystem. Rechecking of the residual is also recommended to determine whether the linear regression will be appropriate given a larger dataset. In the future, the placement of monitoring systems with real-time data drop will serve as an avenue to advance remote sensing research on water. Intensive shore decay analysis is highly recommended in comparison with historical phenomena such as spawning, low fish catch, fish kill, and increase in river mouth nutrients. Finally, uncertainties like the wind effect must be considered in the dispersal of water quality parameters and dynamics of aquatic organisms, specifically the plankton.

\section{ACKNOWLEDGEMENTS}

I would like to acknowledge Dr. Yap and Dr. Mari for inspiring me to get a grip and write this paper amid the COVID-19 pandemic.

\section{REFERENCES}

Alongi, D. M., 2008: Mangrove forests: Resilience, protection from tsunamis, and responses to global climate change. Estuarine, Coastal and Shelf Science, 76(1), 1-3. doi.org/10.1016/j.ecss.2007.08.024.

Amsler, M., \& Drago, E. (2009). A review of suspended sediment budget at the confluence of the Parana and Paraguay Rivers. Hydrological Processes, 23, 3230-3235.

Andrieu, J., Lombard, F., Fall, A., Thior, M., Ba, B., \& Dieme, B. (2020). Botanical field-study and remote sensing to describe mangrove resilience in Saloum Delta (Senegal) after 30 years of degradation narrative. Forest Ecology and Management, Article 117963. doi:https://doi.org/10.1016/j.foreco.2020.117963.

Astel, A., Mazerski, J., Polkowska, Ż., \& Namieśnik, J. (2004). Application of PCA and time series analysis in studies of precipitation in Tricity (Poland). Advances in Environmental Research, 8(3-4), 337-349.

Barbier, E. B., S. D. Hacker, C. K., Koch, E. W., \& Stier, A. C., 2011: The value of estuarine and coastal ecosystem services. Ecological Monographs, 81(2), 169-193. doi.org/10.1890/101510.1

Chen, Y., Li, Y., Thompson, C., Wang, X., Cai, T., \& Chang, Y. (2018). Differential sediment trapping abilities of mangrove and saltmarsh vegetation in a subtropical estuary. Geomorphology, $318,270-282$.

Chu, H.-J., Kong, S.-J., \& Chang, C.-H., 2018: Spatio-temporal water quality mapping from satellite images using geographically and temporally weighted regression. International Journal of Earth Observation and Geoinformation, 65, 1-11. doi.org/10.1016/j.jag.2017.10.001.

Devlin, M., Petus, C., Da Silva, E., Tracey, D., Wolff, N., Waterhouse, J., \& Brodie, J., 2015: Water Quality and River Plume Monitoring in the Great Barrier Reef: Overview of Methods Based on Ocean Colour Satellite Data. Remote Sensing, 7(10), 12909-12941. doi.org/10.3390/rs71012909.

Chesapeake Bay Foundation (2021). Geography and Facts. https://www.cbf.org/about-the-bay/chesapeake-bay-watershedgeography-and-facts.html.

Costanza, R., d'Arge, R., de Groot, R., Farber, S., Grasso, M., Hannon, B., van den Belt, M., 1997: The value of the value of the world's ecosystem services and natural capital. Nature, 387, 253-260. doi.org/10.1038/387253a0.

DENR. (2016). DENR AO 2016-08: Water Quality Guidelines and General Effluent Standards of 2016. Quezon: DENR.

Doan, Q., Nguyen, T., Quach, T., Tran, A., \& C.D.Nguyen. (2019). Assessment of water quality in coastal estuaries under the impact of an industrial zone in Hai Phong, Vietnam. Physics and Chemistry of the Earth, 113, 100-114.

Erkkila, A., \& Kalliola, R. (2004). Patterns and dynamics of coastal waters in multi-temporal satellite images: support to water quality monitoring in th eArchipelago Sea, finland. Estuarine, Coastal and Shelf Science, 60, 165-177. doi:10.1016/j.ecss.2003.11.024. 
Escandor, J. J. (2012, February 1). A mangrove shield against storm surges. Retrieved from Inquirer.Net: https://newsinfo.inquirer.net/138183/a-mangrove-shieldagainst-storm-surges.

Faustino, A., Madela, H., Castor, R., Muroda, A., \& Chavez, M. (2020). Community mapping and vegetational analysis of the mangrove forest in Calabanga, San Miguel Bay, Philippines. E3S Web of Conferences (p. 147). Yogyakarta, Indonesia: EDP Sciences.

Gao, G., Falconer, R., \& Lin, B. (2013). Modelling importance of sediment effects on fate and transport of enterococci in the Severn estuary, UK. Marine Pollution Bulletin, 67(1-2), 45-54.

Gerbersdorf, S., \& Schubert, H. (2011). Vertical Migration of phytoplankton in coastal waters with different UVR transparency. Environmental Sciences Europe, 23, 36.

Hellweger, F., P. Schlosser, U. L., \& Weissel, J. (2004). Use of satellite imagery for water quality studies in New York Estuarine. Coastal Shelf Science, 61(3), 437-448.

Karl, D., Bidigare, R., \& Letelier, R. (2001). Long-term changes in plankton community structure and productivity in the North Pacific Subtropical Gyre: the domain shift hypothesis. Deep Sea Research Part II: Topical Studies in Oceanography, 48(8-9), 1449-1470.

Kim, J., \& Park, J. (2017). Bayesian structural equation modeling for coastal management: The case of the Saemangeum coast of KOrea for water quality. Ocean and Coastal Management, 136, 120-132.

Kloiber, S., Brezonik, P., \& Bauer, M. (2010). Application of Landsat imagery to regional-scale assessments of lake clarity. Water Resources, 36(17), 383-401.

Mallin, M. A., \& McIver, M., 2012: Pollutant impacts to Cape Hatteras National Seashore from urban runoff and septic leachate. Marine Pollution Bulletin, 64(7), 1356-1366. doi.org/10.1016/j.marpolbul.2012.04.025.

Manbohi, A., \& Gholamipour, S. (2020). Utilizing chemometrics and geographical information systems to evaluate spatial and temporal variations of coastal water qualoty. Regional Studies in Marine Science, 34, Article 101077.

Marengo, E., Gennaro, M., Giacosa, D., Saini, G., \& Avignone, M. (1995). How chemometrics can helpfully assist in evaluating environmental data. Lagoon water. Analytica Chimica Acta, 317(1-3), 53-63.

Martinez, M., Intralawan, A., Vasquez, G., Perez-Maqueo, O., Sutton, P., \& Landgrave, R., 2007: The coasts of our world: Ecological, economic and social importance. Ecology and Economics, 63(2-3), doi.org/10.1016/j.ecolecon.2006.10.022.

Mavropoulou, A., Vervatis, V., \& Sofianos, S. (2020). Dissolved oxygen variability in the Mediterranean Sea. Journal of Marine Systems, 208, Article 103348.

Mazda, Y., Wolanski, E., King, B., Sase, A., Ohtsuka, D., \& Magi, M. (1997). Drag force due to vegetation in mangrove swamps. Mangroves Salt Marshes, 1, 193-199.
NASA. (2020). Worldview Snapshots. Retrieved from Earth Data: https://wvs.earthdata.nasa.gov/

NOAA. (2019, October 10). What are phytoplankton? Retrieved from National Ocean Service: https://oceanservice.noaa.gov/facts/phyto.html.

Norat-Ramírez, J., P.Méndez-Lázaro, E.A.Hernández-Delgado, H.Mattei-Torres, \& L.Cordero-Rivera. (2019). A septic waste index model to measure the impact of septic tanks on coastal water quality and coral reef communities in Rincon, Puerto Rico. Ocean and Coastal Management, 169, 201-213.

MeteologixPH. (2020). Observations. Retrieved from MeteologixPH:https://meteologix.com/ph/observations/philippi nes/wind-direction/

Qu, W., \& Kelderman, P. (2001). Heavy metal contents in the Delft canal sedimentas adn suspended solids of the river rhine: multivariate analysis for source tracing. Chemosphere, 45, 764780. doi:http://dx.doi.org/10. 1016/j.scitotenv.2018.06.095.

Richards, D. R., \& Friess, D. A., 2016: Rates and drivers of mangrove deforestation in Southeast Asia, 2000-2012. Proceedings of the National Academy of Sciences of the United States of America, 113(2), 344-349. doi.org/10.1073/pnas.1510272113.

Schalie, W., Shedd, T. K., \& Widder, M. (2001). Using higher organisms in biological early warning systems for real-time toxicity detection. Biosensors and Bioelectronics, 16(7-8), 457465 .

Soltes, J., \& Rodriguez, G. (2010, June 15). Mangroves bring life back to a deserted shore. Retrieved from Pressreader: https://www.pressreader.com/philippines/philippine-dailyinquirer-1109/20100615/282458525205752

van Wesenbeeck, B. K., Balke, T., van Eijk, P., Tonneijck, F., Siry, H., Winterwerp, J., \& Rudianto, M., 2015: Aquaculture induced erosion of tropical coastlines throws coastal communities back into poverty. Ocean and Coastal Management, $\quad 116, \quad 466-469$. doi.org/10.1016/j.ocecoaman.2015.09.004.

Veettil, B. K., \& Quan, N. X., 2019: Mangrove forests of Cambodia: Recent changes and future threats. Ocean and Coastal Management, 181, Article 104895. doi.org/10.1016/j.ocecoaman.2019.104895.

Ward, R., Friess, D., Day, R., \& Mackenzie, R. (2016). Impacts of climate change on mangrove ecosystems: a region by region overview. Ecosystem Health Sustainability, 2(4), Article e01211. doi:https://doi.org/10.1002/ehs2.1211.

Winterwerp, J., Erftemeijer, P., Suryadiputra, N., Eijk, P. v., \& Zhang, L. (2013). Defining eco-morphodynamic requirements for rehabilitating eroding mangrove-mud coasts. Wetlands, 33, 515-526. 